\title{
Prenatal and Postnatal Methylmercury Exposure in Niigata, Japan: Four Cases Descriptive Study
}

\section{Kimio Maruyama ${ }^{1 *}$, Hisashi Saito ${ }^{2}$ and Naoji Hagino ${ }^{2}$}

${ }^{1}$ Niigata Seiryo University, Suido-cho, Central Ward, Niigata City, Japan

${ }^{2}$ Kido Hospital, 4-13-3, Takeo, East Ward, Niigata City 950-0862, Japan

\begin{abstract}
Large-scale MeHg poisoning occurred in Niigata, Japan in the 1960s. Hair mercury levels were measured early in the epidemic of $\mathrm{MeHg}$ poisoning. The severe prenatal exposure cases with conditions resembling cerebral palsy, i.e., congenital Minamata disease are well-known, although severe prenatal and postnatal MeHg exposure cases who did not develop such severe symptoms are not well-known. We conducted follow-up neurologic examinations and interviews of four participants with a history of prenatal and postnatal $\mathrm{MeHg}$ exposure who had-along with their mothers undergone hair mercury measurement in June 1965 . We describe their development and subjective symptoms in childhood and neurologic signs in adulthood. The hair mercury levels of the four participants ranged from 63.0 to $111.0 \mathrm{ppm}$ in 1965 , and maternal levels ranged from 58.0 to $275.0 \mathrm{ppm}$. Although the four participants had high prenatal and postnatal $\mathrm{MeHg}$ exposures, they did not develop severe symptoms resembling cerebral palsy. They had symptoms such as poor concentration and poor memory which are thought to be neuropsychological dysfunction, as well as $\mathrm{MeHg}$ poisoning in childhood. One was intellectually impaired (Total IQ, 79). Nearly 50 years after prenatal and postnatal MeHg exposure, they had neurologic signs such as sensory disturbances of the bilateral distal extremities and blurred vision. There are several limitations such as a possibility of selection bias, etc. in the present study. 4 cases had various signs and symptoms possibly due to prenatal and postnatal MeHg exposure such as neurologic signs and neuropsychological dysfunction during lifetime.
\end{abstract}

Keywords: Methylmercury; Prenatal and postnatal; Mercury; Subjective symptoms; Neurologic signs; Minamata disease

\section{Introduction}

Large-scale methylmercury (MeHg) poisoning from fish consumption occurred in Japan at Minamata (Minamata disease), in the 1950s, and at Niigata, in the 1960s (Figure 1) [1-6]. The MeHg

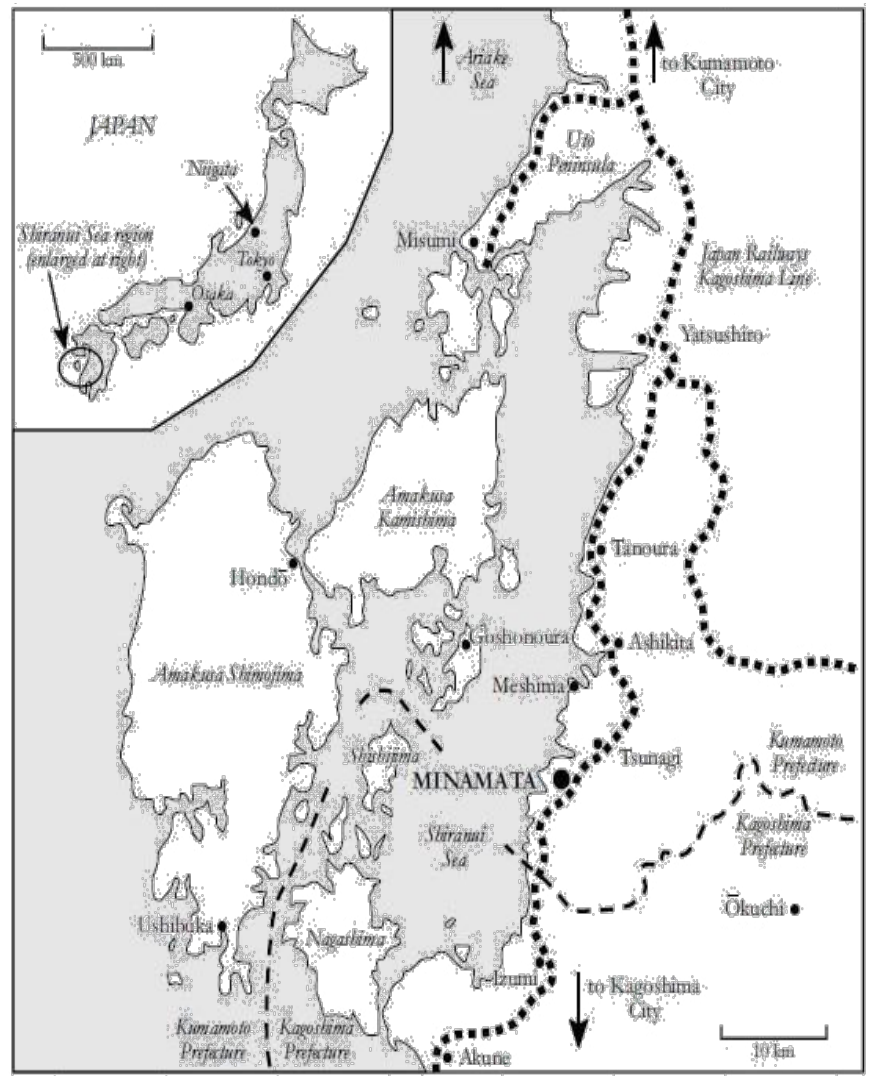

Figure 1: Map of Minamata and Niigata in Japan Source: [10] poisoning in Niigata is less well known internationally than the event in Minamata [7]. Data on $\mathrm{MeHg}$ exposure in Minamata are very limited. In contrast, since at Niigata the cause was recognized early in the epidemic of $\mathrm{MeHg}$ poisoning, $\mathrm{MeHg}$ exposure could be examined by hair mercury levels $[7,8]$.

Before the epidemic of $\mathrm{MeHg}$ poisoning in Niigata, residents in the Agano River basin consumed fish and shellfish from the river for their daily meals. Fishing was part of the livelihood of most residents, and fish and shellfish from the river were an essential source of protein $[9,10]$.

The first case of $\mathrm{MeHg}$ poisoning in Niigata was identified in January 1965. Seven cases were confirmed before June 1965, and all lived around the lower stream of the Agano River [2-6]. Their exposure was due to consumption of fish and shellfish contaminated by $\mathrm{MeHg}$ discharged from the Showa Denko Kanose Factory (Showa Denko) located in the town of Kanose, about $65 \mathrm{~km}$ from the mouth of the Agano River (Figure 2) [2-6]. Showa Denko began producing acetaldehyde in 1936, using $\mathrm{Hg}$ as a catalyst (Figure 3), and $\mathrm{MeHg}$ had been produced as a byproduct of acetaldehyde production. The factory discharged effluent contaminated by $\mathrm{MeHg}$ into the Agano River. As shown in Figure 3, acetaldehyde production peaked at 19,476 tons in 1964 [10]. Samples of fish collected from the Agano River in June 1965 had high total mercury levels (barbel, 21.0-23.6 ppm; snakehead mullet, $12.3 \mathrm{ppm}$; club, 4.6-8.38 ppm; and eel, $41.0 \mathrm{ppm}$ ) [11]. At the time, there were about 2,000 fishermen in the Agano River basin [10].

*Corresponding author: Kimio Maruyama, Department of Social Welfare and Psychology, Niigata Seiryo University, Central Ward, Niigata City, Japan, Tel: +8125-267-0053; E-mail: k-maruyama@n-seiryo.ac.jp

Received March 02, 2015; Accepted April 22, 2015; Published April 24, 2015

Citation: Maruyama K, Saito H, Hagino N (2015) Prenatal and Postnatal Methylmercury Exposure in Niigata, Japan: Four Cases Descriptive Study. J Clin Case Rep 5: 520. doi:10.4172/2165-7920.1000520

Copyright: (c) 2015 Maruyama K, et al. This is an open-access article distributed under the terms of the Creative Commons Attribution License, which permits unrestricted use, distribution, and reproduction in any medium, provided the original author and source are credited. 


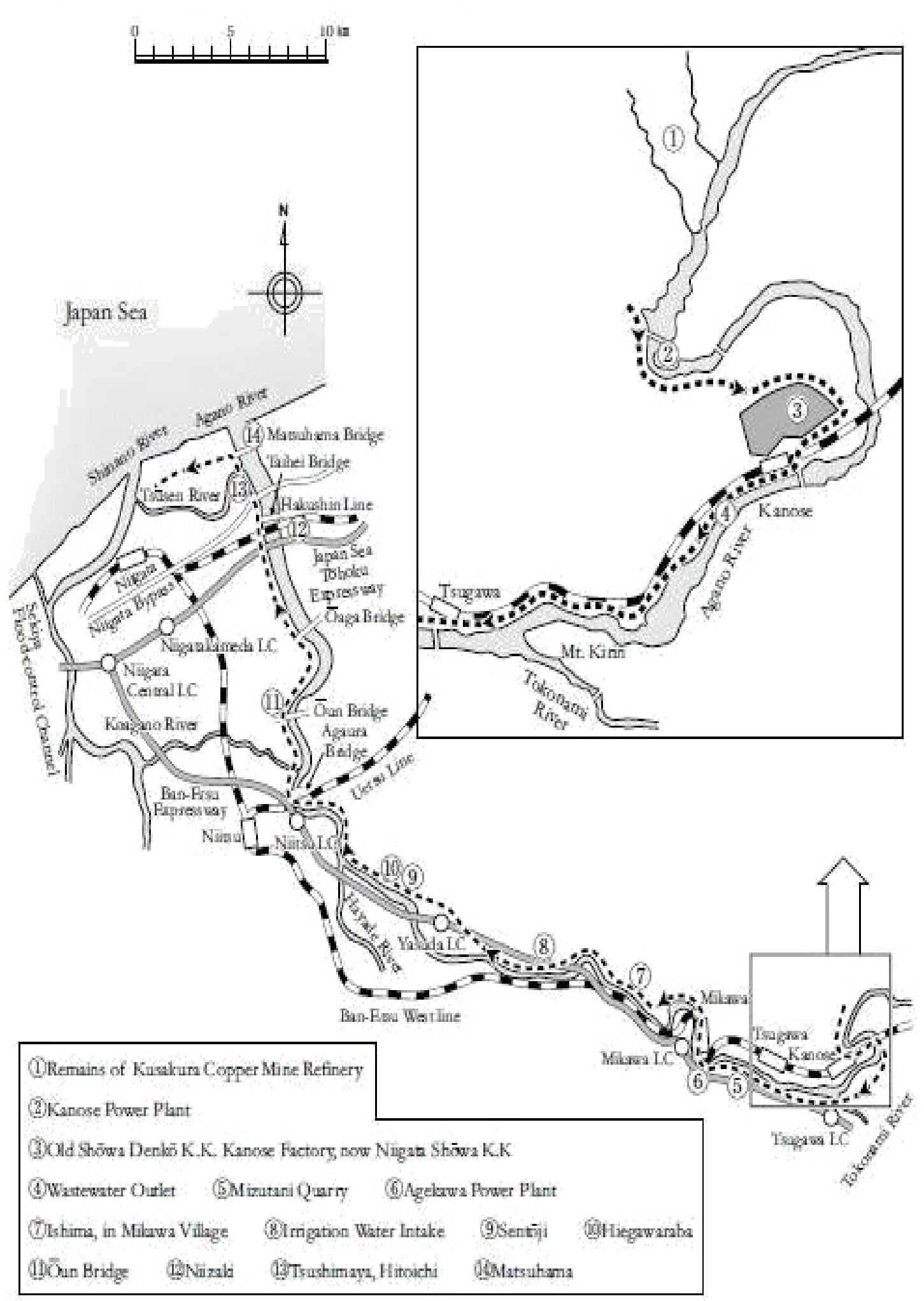

Figure 2: Map of study area. Source: [10].

Two surveys were carried out for all officially-registered inhabitants of administrative districts located within $15 \mathrm{~km}$ of the mouth of the Agano River, where the seven cases lived in June 1965. From these two surveys total hair mercury content of 1,458 persons was measured [2-
6,11]. 26 adult cases were officially recognized as having Minamata disease based on their subjective symptoms and neurologic signs from these surveys. The hair mercury level of these cases ranged from 56.8 ppm to $570 \mathrm{ppm}$. These data were cited in two Environmental Health 
( ton/year)

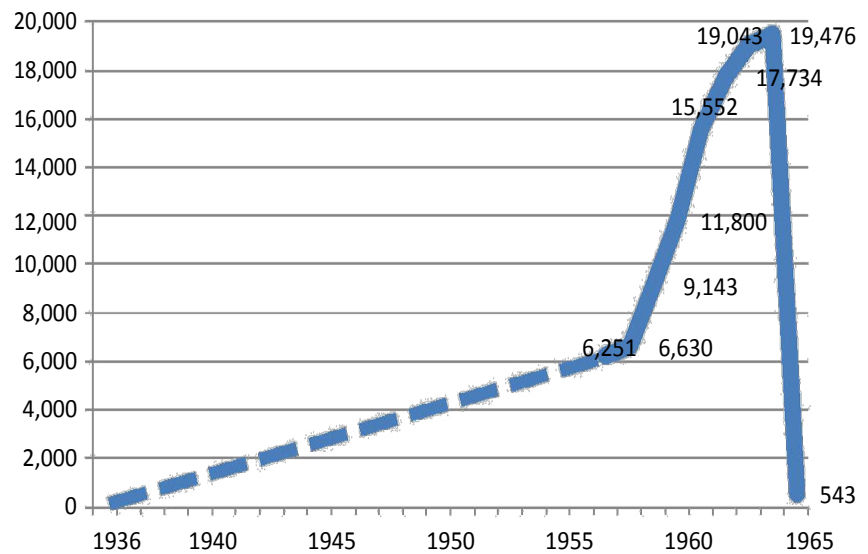

Figure 3: Acetaldehyde annual amount of production of Showa Denko Source: [10].

(a) Patients had eaten large amounts of fish from the Agano

(b) River before the neurological signs and symptoms occurred High mercury levels in hair (or blood or urine)*

(c) The following neurological signs were present*2

(1) Sensory disturbance (paresthesia, hypesthesia)

(2) Constriction of the visual field

(3) Hearing impairment

(4) Cerebellar signs (impairment in speech and gait, disequilibrium and ataxia)

(d) Other diseases having similar signs and symptoms were excluded*3

*1 Mercury levels were back to normal within several months when intake of mercury was terminated. The mercury levels, therefore, should be considered in relation to the period of river fish intake. If mercury levels during the period concerned cannot be identified, the levels should be estimated in relation to the conditions under which the patients lived. For example, other family member(s) may be poi-soned or have high levels of mercury in the hair, etc.

*2 Not necessarily showing all 4 of the signs indicated. High frequency of sensory disturbance, especially in the extremities, perioral area and tongue is indicative, and is difficult to remedy.

*3 Especially noteworthy are polyneuritis of various origins, cerebrovascular disturbance, cervical spondylosis and psychogenic disorders. In cases where the signs cannot be explained by such diseases alone, even when the patients have the disease, the cases can be diagnosed as methylmercury poisoning. $(2,6,14)$.

Table 1: Diagnostic Criteria for Methylmercury Poisoning in Niigata.

Criteria reports, in 1976 and 1990 [2-6,8-13]. Tsubaki proposed diagnostic criteria for $\mathrm{MeHg}$ poisoning in Niigata based on these surveys subsequently (Table 1 ) $[2,6,14]$. The Tsubaki's criteria defines $\mathrm{MeHg}$ poisoning extensively, rather than the rigid set of criteria for Minamata disease known as the "1977 Criteria" for adjudicating on cases of Minamata disease for health damage compensation from the Judgment Committee for Minamata Disease Certification, which require a combination of neurologic signs [15]. The Tsubaki's criteria well conform to actual cases of $\mathrm{MeHg}$ poisoning. Niigata Prefecture restricted the catching of fish and shellfish from July 1, 1965.

In July 1965, Niigata Prefecture conducted a health survey of infants and women of reproductive age (15-49), including pregnant women and nursing mothers, who lived in the lower basin of the Agano River (within $15 \mathrm{~km}$ of the river mouth) [2-6]. The surveys revealed that one infant, with a hair mercury level of $77 \mathrm{ppm}$, had signs of cerebral palsy. The infant that congenital Minamata disease was suspected was
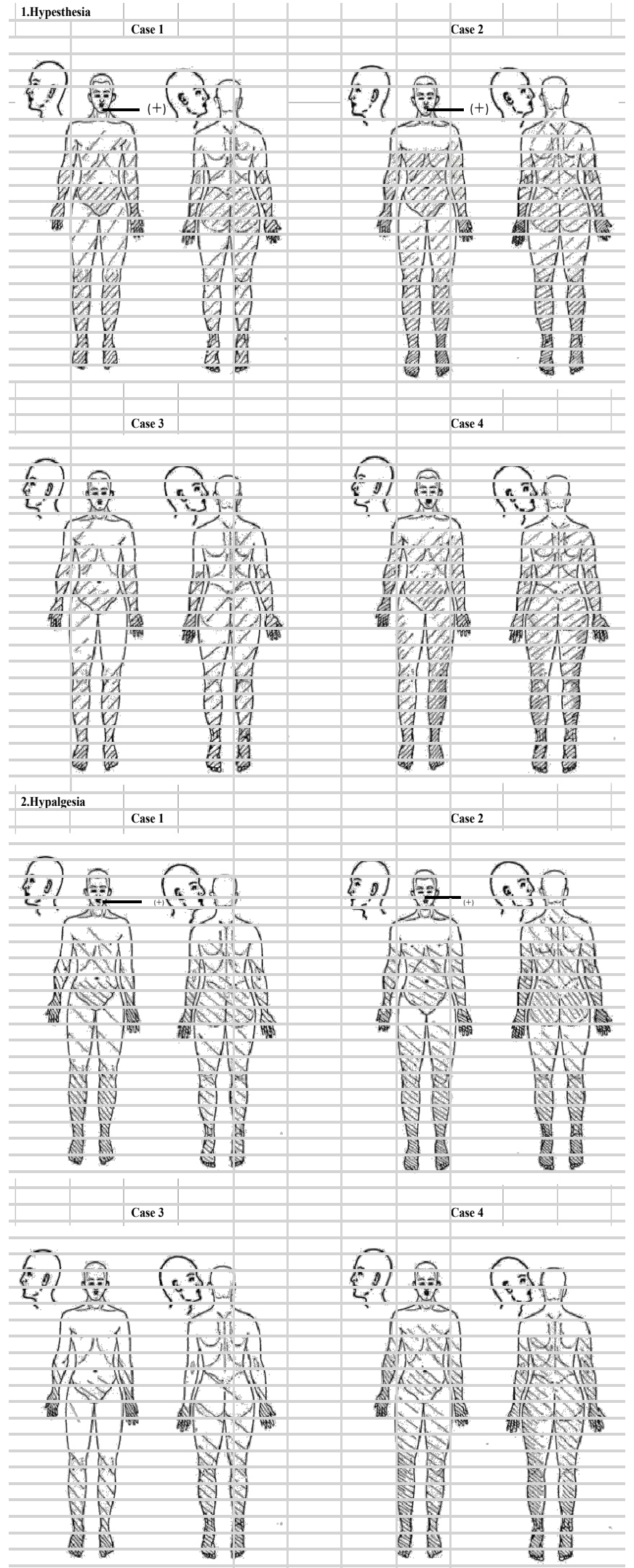

Figure 4: Sensory disturbances of the four participants The parts indicated in oblique lines shows hypesthesia and hypalgesia. (+) shows hypesthesia and hypalgesia in perioral area. 
subsequently officially recognized as having congenital Minamata disease $[2-6,11]$.

The large-scale MeHg poisoning in Minamata showed that fetal exposure was especially dangerous [16]. A considerable number of children were born with conditions resembling cerebral palsy, i.e., congenital Minamata disease, and exhibited intellectual impairment, mood and behavioral dysfunction, neurologic signs, and motor disturbance [16,17], although severe prenatal and postnatal $\mathrm{MeHg}$ exposure cases who did not develop such severe symptoms were unknown.

We conducted follow-up neurologic examinations and interviews of four persons with a history of severe prenatal and postnatal $\mathrm{MeHg}$ exposure. We describe their development and subjective symptoms in childhood, family history, life history, and neurologic signs in adulthood.

\section{Materials and Methods}

\section{Study area and participants}

We selected the four participants with a history of prenatal and postnatal $\mathrm{MeHg}$ exposure who had-along with their mothersundergone hair mercury measurement in June 1965. They now voluntarily consult at local medical institution (Kido hospital) with symptoms related to $\mathrm{MeHg}$ poisoning as chief complaints for medical care.The present four participants were born into fishing families and lived within $4 \mathrm{~km}$ of the river mouth. Their mothers consumed fish and shellfish from the river during pregnancy. Accordingly, the four participants were exposed to prenatal $\mathrm{MeHg}$, and after birth, they were exposed to $\mathrm{MeHg}$ through breast feeding. Case 2, 3, and 4 were exposed to $\mathrm{MeHg}$ through fish consumption in childhood.

\section{Measurement of $\mathrm{MeHg}$ in hair}

Mercury content in hair samples was measured using the Dithizone method at Niigata University in June 1965 [2-6,18].

\section{Measurement of outcomes}

In the present study, neurologic signs of the four participants were evaluated using a standard neurologic examination by one of the authors (H.S.) [8], a physician, between 2011 and 2014. They were then interviewed using a standardized questionnaire, and asked about their clinical, family, and life history in June 2014. The questionnaire is shown in Table 2. The questionnaire explored the person's development and subjective symptoms in childhood. The items were then classified into general categories, as illustrated in Table 3.

\section{Case Reports}

\section{Case 1}

A 49-year-old woman; the second of two children. Her mother's condition was normal during pregnancy and delivery, and she weighed 2,800 grams at birth. Her father was a fisherman on the Agano River. Two months after her birth (June 1965), the total hair mercury levels of the family were measured using the Dithizone method. The levels were $118.0 \mathrm{ppm}$ in her father, $66.4 \mathrm{ppm}$ in her mother, $46.0 \mathrm{ppm}$ in her brother, and $63.0 \mathrm{ppm}$ in the participant. Later her parents, grandparents, and brother were officially recognized as having Minamata disease. Although she was initially bottle-fed, her mother began breast feeding since she vomited the milk. Although she appeared to be a healthy baby, she was given penicillamine and 2-mercaptopropionyl glycine for 2 to 3 weeks at Niigata University Hospital because her hair mercury level

\begin{tabular}{|l|}
\hline As a child did you lose your balance easily? \\
\hline As a child did you have difficulty walking in the dark? \\
\hline As a child did you have any vision problems? \\
\hline As a child did you have any hearing problems? \\
\hline As a child did you have muscle cramps? \\
\hline As a child did you have troble using chopsticks? \\
\hline As a child did you have tremors? \\
\hline As a child did you have frequent headache? \\
\hline As a child were you often irritable? \\
\hline As a child did you have dizziness on standing? \\
\hline As a child did you have any numbness of legs? \\
\hline When eating, did you drop food frequently? \\
\hline Did you get carsick? \\
\hline Did you drop teacups or dishes often? \\
\hline Was it difficult for you to sit on a chair in a classroom? \\
\hline Were you able to concentrate and study well? \\
\hline When dressing, have you had difficulty with buttons? \\
\hline Have you had cramping of your calf muscles? \\
\hline What is your final academic background ? \\
\hline How were you getting on at school ? \\
\hline Were you able to find a job easily ? \\
\hline At what age did you start crawing ? \\
\hline At what age did you begin walking ? \\
\hline At what age did you begin talking ? \\
\hline
\end{tabular}

Table 2: Questionnaire.

\begin{tabular}{|c|c|}
\hline Category & Questions \\
\hline \multirow{2}{*}{ Delayed walking } & At what age did you start crawing? \\
\hline & At what age did you begin walking? \\
\hline Delayed speech & At what age did you begin talking? \\
\hline \multirow{2}{*}{ Muscle cramps } & As a child did you have muscle cramps? \\
\hline & Have you had cramping of your calf muscles? \\
\hline Irritability & As a child were you often irritable? \\
\hline \multirow{2}{*}{ Tendency to stumble } & As a child did you lose your balance easily? \\
\hline & As a child did you have difficulty walking in the dark? \\
\hline Headache & As a child did you have frequent headache? \\
\hline Numbness & As a child did you have any numbness of legs? \\
\hline Dizziness & As a child did you have dizziness on standing ? \\
\hline \multirow{4}{*}{ Impaired fine motor skills } & As a child did you have trouble using chopsticks? \\
\hline & When eating, did you drop food frequently? \\
\hline & Did you drop teacups or dishes often? \\
\hline & When dressing, have you had difficulty with buttons? \\
\hline Car sickness & Did you get carsick? \\
\hline Tremor & As a child did you have tremors? \\
\hline \multirow[t]{2}{*}{ Poor concentration } & Were you able to concentrate and study well ? \\
\hline & Was it difficult for you to sit on a chair in a classroom? \\
\hline Poor memory & How were you getting on at school? \\
\hline \multirow[t]{2}{*}{ Disturbed vision or hearing } & As a child did you have any vision problems? \\
\hline & As a child did you have any hearing problems? \\
\hline
\end{tabular}

Table 3: Classification of question items.

was high. As she did not consume contaminated fish during childhood, she was not exposed to $\mathrm{MeHg}$ in childhood. Her development was relatively delayed: she began walking at age 20 months, first spoke at age 30 months, and received toilet training between the ages of 3 and 4 years. She was small and was often unwell during childhood. She tended to tire easily, had muscle cramps and twitching in her extremities, and had frequent back pain. She often complained of headaches and tinnitus. In the second and third grades of elementary school she 
developed occasional vertigo and became unable to play on swings at school because it worsened her feeling. She also complained of motion sickness when riding in cars. While in elementary school, she reported numbness in her limbs and poor sensation in her fingers. She did not like manual work or art. In addition, she began to have insomnia and became irritable and quick-tempered. Her vision blurred when she stared at something. She sometimes fainted suddenly but recovered in about 5 minutes. At school, her memory and academic and athletic performance were poor. She reached menarche at age 12, married at age 23, and had two healthy children. Although she continues to have various symptoms, she is employed. At age 47 , she had frequent numbness in the extremities and muscle cramps, episodes of vertigo, tinnitus, and arthralgia in the hands and fingers. Her vision continued to blur when she stared at something but improved when she diverted her attention to something else. Her family members indicated that she is slow at walking and speaking (Table 4).

Neurologic signs: At age 8, she had sensory disturbances in the bilateral distal extremities. At age 30, she had sensory disturbances in the perioral area, lower abdomen, gluteal region, the left side of her body, and bilateral distal extremities, along with disequilibrium and blurred peripheral vision. At age 40, she had sensory disturbances in the lower abdomen, gluteal region, right side of her body, and bilateral distal extremities. Two-points discrimination was slightly impaired at the lower lip [19]. Tongue movement was poor, and she had disequilibrium. Her peripheral vision was blurred. Her neurologic signs at age 48 are shown in Table 5 and Figure 4.

\section{Case 2}

A 54-year-old man; the third of three children (Case 4 is his elder sister). His mother's condition was normal during pregnancy and delivery. He was breast-fed up to age 2 months and then given bottle feeding. His development was delayed. In June 1965 total hair mercury levels were measured in the family. The mercury level was $58.0 \mathrm{ppm}$ in his mother, $178.0 \mathrm{ppm}$ in his eldest sister, $95.0 \mathrm{ppm}$ in his second-eldest sister (Case 4), and $111.0 \mathrm{ppm}$ in the participant. His father and grandfather were fishermen on the Agano River. The family had two cats, which began running in circles, as though they were mad, and died in the spring and autumn of 1964. In June 1964

\begin{tabular}{|c|c|c|c|c|}
\hline Case & 1 & 2 & 3 & 4 \\
\hline Sex & Female & Male & Female & Female \\
\hline DOB: $\mathrm{d} / \mathrm{m} / \mathrm{y}$ & $8 / 4 / 1965$ & $27 / 6 / 59$ & $29 / 7 / 59$ & $14 / 12 / 54$ \\
\hline Hair mercury content of the subject in June 1965 (ppm) & 63 & 111 & 110 & 95 \\
\hline Hair mercury content of the subject's mother in June 1965 (ppm) & 66.4 & 58 & 275 & 58 \\
\hline Age in years of measure of hair mercury content & $2 m$ & $6 y$ & $6 y$ & $10 y$ \\
\hline Age in years of interview & $49 y$ & $54 y$ & $54 y$ & $59 y$ \\
\hline \multicolumn{5}{|l|}{ Family history } \\
\hline Occupation of family & Fisherman & Fisherman & Fisherman & Fisherman \\
\hline Hair mercury content of families (ppm) & $\begin{array}{l}\text { F; } 118.0 \\
\text { Bro; } 46.0\end{array}$ & $\begin{array}{c}\mathrm{S} ; 178.0 \\
\text { case } 4 ; 95.0\end{array}$ & $\begin{array}{c}\text { GF; } 152.0 \\
F ; 378.0\end{array}$ & $\begin{array}{c}\mathrm{S} ; 178.0 \\
\text { case } 2 ; 111.0\end{array}$ \\
\hline Consumption of Agano river's fish & - & every day & every day & every day \\
\hline Family members officially diagnosed as having $\mathrm{MeHg}$ poisoning & GF, GM, F,M, Bro & GF, GM, F,M & GF, F, M,Bro, S & GF, GM, F,M \\
\hline Breastfed & + & + & + & + \\
\hline Bottle fed & + & + & - & + \\
\hline Month started & 5 & 2 & - & 3 \\
\hline Delayed walking & $20 \mathrm{~m}$ & + & UK & + \\
\hline Delayed speech & $30 m$ & + & UK & + \\
\hline \multicolumn{5}{|l|}{ Subjective symptoms in childhood } \\
\hline 1. Muscle cramps & + & + & + & + \\
\hline 2. Irritability & + & + & - & + \\
\hline 3. Tendency to stumble & + & + & + & - \\
\hline 4. Headaches & + & + & + & + \\
\hline 5. Numbness & + & + & + & - \\
\hline 6. Dizziness & + & + & + & + \\
\hline 7. Impaired fine motor skills & + & + & + & + \\
\hline 8. Car sickness & + & + & + & + \\
\hline 9. Tremor & - & + & - & - \\
\hline 10. Poor memory & + & + & + & + \\
\hline 11. Poor concentration & + & + & + & + \\
\hline 12. Disturbed vision or hearing & $\begin{array}{l}\text { Blurred } \\
\text { vision, } \\
\text { Tinnitus }\end{array}$ & $\begin{array}{l}\text { Blurred } \\
\text { vision, } \\
\text { Tinnitus }\end{array}$ & $\begin{array}{l}\text { Blurred } \\
\text { vision, } \\
\text { Tinnitus }\end{array}$ & $\begin{array}{l}\text { Blurred } \\
\text { vision, } \\
\text { Tinnitus }\end{array}$ \\
\hline Education & High School Graduate & $\begin{array}{l}\text { Middle school } \\
\text { graduate, special } \\
\text { support class }\end{array}$ & $\begin{array}{l}\text { High School } \\
\text { graduate }\end{array}$ & $\begin{array}{l}\text { High School } \\
\text { graduate }\end{array}$ \\
\hline Occupation & Company employee & none & Housewife & Housewife \\
\hline Other & $\begin{array}{l}\text { Susceptibility to } \\
\text { infections }\end{array}$ & $\begin{array}{l}\text { impairment } \\
\text { of intelligence }\end{array}$ & Depression & $\begin{array}{l}\text { Susceptibility } \\
\text { to infections }\end{array}$ \\
\hline
\end{tabular}

Table 4: Demographic characteristics, hair mercury,maternal hair mercury, family history, life history, development and subjective symptoms of the four participants. 


\begin{tabular}{|c|c|c|c|c|}
\hline Case & 1 & 2 & 3 & 4 \\
\hline Age in years of assessment of neurologic signs & $48 y$ & $54 y$ & $51 y$ & $58 y$ \\
\hline \multicolumn{5}{|l|}{ Neurologic signs } \\
\hline sensory disturbance & Figure 4 & Figure 4 & Figure 4 & Figure 4 \\
\hline Two-points discrimination at the lower lip (mm) & 3 & 6 & 10 & 6 \\
\hline \multicolumn{5}{|l|}{ Incoordination } \\
\hline Adiadochokinesis & - & - & - & - \\
\hline Finger-Nose test & - & - & - & - \\
\hline Heel-Knee test & - & - & - & - \\
\hline \multicolumn{5}{|l|}{ Disequilibrium } \\
\hline Romberg test (eyes open) & - & - & - & - \\
\hline Romberg test (eyes closed) & + & - & - & - \\
\hline Mann test (eyes open) & - & - & - & - \\
\hline Mann test (eyes closed) & + & + & + & - \\
\hline Standing on One Foot of rt. side (eyes open) & - & - & - & - \\
\hline Standing on One Foot of It. side (eyes open) & - & - & - & - \\
\hline Standing on One Foot of rt. side (eyes closed) & + & + & + & \pm \\
\hline Standing on One Foot of It. side (eyes closed) & + & + & + & - \\
\hline \multirow[t]{2}{*}{ Eye movement } & intact & saccadic & intact & saccadic \\
\hline & Blurred & Blurred & Blurred & Blurred \\
\hline \multirow[t]{2}{*}{ Impairment of visual field } & peripheral & total & peripheral & peripheral \\
\hline & vision & vision & vision & vision \\
\hline Impairment of hearing & rt. - It. + & bil. + & bil. - & bil. + \\
\hline Gait disturbance & - & - & - & - \\
\hline Tremor & - & + & + & - \\
\hline Fluctuation in neurologic signs & + & - & - & - \\
\hline Delayed neurotoxicity & - & - & - & + \\
\hline
\end{tabular}

$+=$ positive $-=$ negative $\pm=$ equivotal $r$.=right It.=light bil.=bilateral

Table 5: Neurologic signs of the four participants.

his grandfather developed symptoms of fulminant Minamata disease and died in October of the same year. His grandmother also developed symptoms of the disease in June 1964 and was officially recognized as having Minamata disease. Both his parents were also recognized as having Minamata disease. His grandfather went fishing daily, and his grandmother sold the fish. All family members abundantly consumed fish from the Agano River every day. His grandfather doted on him-as he was the first and only male grandchild-letting him sit next to him at the supper table and giving him a great deal of fish. He was exposed to $\mathrm{MeHg}$ through fish consumption in childhood. In his earliest memories, he often stumbled. At age 5 or 6 , he developed headaches, numbness in the extremities, occasional vertigo, and nausea. In pre-school he was bullied and excluded from the group. In elementary school he did not join athletic events because running resulted in vertigo. When he did run, he veered toward the right. After sitting for an hour in his classes, he felt headache and then nausea. Consequently he was obliged to rest in the school nurse's office. When he was in the second or third grade of elementary school, he developed tinnitus and hearing impairment. His memory and academic performance were poor. He was transferred to a special education class in fourth grade and was bullied in elementary school. Before entering junior high school he developed hand tremors and muscle cramps, particularly in his calves. In junior high school, he also attended special education classes. His academic performance was poor. He received poor grades in Japanese language, English, mathematics, social science, and natural science. Because of headaches, he often had to rest in the school nurse's office. After graduating from junior high school, he enrolled in a vocational school and evening classes for senior high school. However, he quit vocational school afte
1 year and senior high school within 2 years because he was unable to understand the content. Later, he mostly worked in the construction industry but changed jobs frequently. He is unmarried. Psychological testing at age 50 revealed a Total IQ of 79 (Verbal IQ, 79; Performance IQ, 84).

Neurologic signs: At age 30, he had sensory disturbances in the perioral area, tongue tip, central lower abdomen, gluteal region, left side of his body, and bilateral distal extremities. His eye movements were saccadic. In equilibrium tests, he was unstable when standing on one foot with both eyes closed. His peripheral vision was blurred. At age 45 , he had sensory disturbances in the lower abdomen, gluteal region, left side of his body, and bilateral distal extremities. Two-points discrimination at the lower lip was impaired. His eye movements were saccadic. His performance in the finger-nose test was slightly poor. On equilibrium testing, the Mann test and standing-on-one-foot test were positive when both eyes were closed. Peripheral vision was blurred, and he had hand tremor. His neurologic signs at age 54 are shown in Table 5 and Figure 4.

\section{Case 3}

A 54-year-old woman; the fifth of five children. Her father and grandfather were fishermen on the Agano River. In June 1965 the total hair mercury levels of the family were measured. The levels were 152.0 ppm in her grandfather, $378.0 \mathrm{ppm}$ in her father, $275.0 \mathrm{ppm}$ in her mother, and $110.0 \mathrm{ppm}$ in the participant. Her grandfather, both parents, and the eldest brother were officially recognized as having Minamata disease. As she had consumed fish from the Agano River daily in childhood, she was exposed to $\mathrm{MeHg}$. When she was in the first grade 
of elementary school, she felt sick and experienced vertigo whenever she played on swings. She also felt sick when doing somersaults during gymnastics. When she was in the fifth grade of elementary school she was bullied by her classmates who had seen information on her examination for Minamata disease on television. After that she had frequent headaches, vertigo, numbness in the extremities, and leg cramps. She often became fatigued and always felt listless. In the first grade of junior high school she began to have daily headaches. She often rested in the school nurse's office in the morning due to strong vertigo. Although she joined the basketball team and was selected as a regular player, she often felt fatigued and was unable to move her body at will. She began to have hyperventilation, which caused her to be depressed. She became unable to enjoy her life and felt extremely pessimistic about her future. She could not sleep well and cried occasionally. At school, she had a poor memory. Although she joined the basketball team again in senior high school, she had hyperventilation more frequently. She felt listless and weak, often got injured, and had constant headaches. After graduating from senior high school, she was employed as an office worker and married at age 29. She gave birth to two healthy boys. At age 42, she developed shoulder pain, which led to sleeplessness, and had more episodes of hyperventilation. She suffered with low mood. At age 45, she felt pain throughout her body and felt unable to move. At age 46, she voluntarily consulted at Kido Hospital for symptoms of $\mathrm{MeHg}$ poisoning, and was diagnosed as having Minamata disease. Later, she was diagnosed as having depression at the department of psychosomatic medicine, for which medication was prescribed.

Neurologic signs: At age 46, she had sensory disturbance of the bilateral distal extremities, right side of her body, and right side of the tongue. Two - points discrimination at the lower lip was slightly impaired. She showed no signs of incoordination or disequilibrium, although her peripheral vision was blurred. Her neurologic signs at age 51 are shown in Table 5 and Figure 4.

\section{Case 4}

A 59-year-old woman (the elder sister of case 2): the second of three children. Her mother's condition was normal during pregnancy and delivery. At birth,she weighed about 2,000 grams. She was breastfed up to the age of 3 months, and then she was given bottle feeding and breast feeding. However her mother did not have sufficient breast feeding, and she was therefore fed with fish broth mixed with rice powder. Her development was delayed. She was still not walking at age 15 months. Speech development was also delayed. Her family history is described above (case 2). She was exposed to $\mathrm{MeHg}$ through fish consumption in childhood. Her hair mercury level was $95.0 \mathrm{ppm}$ in June 1965. Since childhood, she often had headaches in the morning. She often cried at night, had little appetite, and often vomited. Because of malnutrition, she was thin, small, and frequently ill. Because she often had fever, her grandmother told her mother that she might not live long. However, while at elementary school she grew less susceptible to illness and reached normal developmental milestones. Nevertheless, she stuttered and felt sick when she played on swings or did somersaults in gymnastics. It was difficult for her to remain seated for more than an hour in class. Because of headaches, she often left school to rest at home during school hours. She was not good at manual work such as craftwork and asked a family friend to do homework that required sewing. She had muscle cramps in the extremities, headaches, vertigo, tinnitus, and blurred vision. At school her memory, academic performance, and athletic performance were poor, as compared with her peers. After graduating from senior high school, she married at age 21 and gave birth to three healthy children. At age 44, she began to feel numbness in the extremities, especially during cold periods. She also began to feel dizziness more frequently.

Neurologic signs: At age 49, she had no sensory disturbance of the bilateral distal extremities. Two-points discrimination at the lower lip was impaired. Eye movements were saccadic. At age 55, she had sensory disturbance of the bilateral distal region of the forearms and lower to distal regions of both legs. Eye movements were saccadic. Her neurologic signs at age 58 are shown in Table 5 and Figure 4.

\section{Results and Discussion}

The demographic characteristics, hair mercury, maternal hair mercury, family history, life history, development and subjective symptoms of the four participants are shown in Table 4 . The neurologic signs of the four participants are shown in Table 5 and Figure 4. Total hair mercury levels were measured in the four participants in June 1965 early in the epidemic of $\mathrm{MeHg}$ poisoning in Niigata. At that time, their ages ranged from 2 months to 10 years, and their hair mercury levels ranged from 63.0 to $111.0 \mathrm{ppm}$, while their maternal levels ranged from 58.0 to $275.0 \mathrm{ppm}$. High-level $\mathrm{MeHg}$ exposure was found in both the participants and their mothers. Moreover, their family members also had high total mercury content levels, which ranged from 46.0 to 378.0 ppm. All family members except for the sibling of cases 2 and 4 were officially recognized as having Minamata disease.

Niigata Minamata disease was caused by consumption of fish and shellfish contaminated by $\mathrm{MeHg}$. Fishermen and their families consumed very large amounts of fish and shellfish from the river. As a result, Minamata disease had a strong tendency toward familial clustering, as seen in the families of the four participants $[20,21]$. The family business of the four participants was fishing. Case 1 did not consume contaminated fish during childhood. We suspect that she was primarily exposed to prenatal $\mathrm{MeHg}$ through the placenta and, after birth she was probably exposed to $\mathrm{MeHg}$ through breast feeding. When total hair mercury levels were measured in June 1965, cases 2 and 3 were 6 years of age, and case 4 was 10 years of age. Showa Denko began discharging $\mathrm{MeHg}$ into the Agano River in 1936. The factory later increased acetaldehyde production [10]. Thus, fish and shellfish in the Agano River were exposed to high $\mathrm{MeHg}$ concentrations (e.g., barbel, 21.0-23.6 ppm; snakehead mullet, $12.3 \mathrm{ppm}$; club, 4.6-8.38 ppm; and eel, $41.0 \mathrm{ppm}$ in June 1965 [11]). As mentioned above, through consumption of contaminated fish and shellfish, mothers were exposed to a high level of $\mathrm{MeHg}$, which led to prenatal $\mathrm{MeHg}$ exposure in the participants. After birth, case 2, 3 and 4 were exposed to $\mathrm{MeHg}$ through breast feeding and fish consumption for several years in childhood.

All four participants complained of muscle cramps, headaches, dizziness, impaired fine motor skills, car sickness, poor memory, poor concentration, and disturbed vision or hearing. Prenatal MeHg exposure is associated with neuropsychological dysfunction in the domains of attention and memory [22]. Poor memory and concentration in the participants might be due to neuropsychological dysfunction caused by high prenatal MeHg exposure. Subjective symptoms such as muscle cramps, dizziness, impaired fine motor skills, and disturbed vision or hearing are more prevalent among individuals who have Minamata disease [23]. Cases 1, 2, and 4 had developmental delays. Cases 1 and 4 had frequent fevers and colds during childhood and were probably susceptible to infection. Case 2 is intellectually disabled and has borderline intellectual functioning (Total IQ, 79). The prevalence of intellectual impairment among adolescents born in the exposed area was higher than in an unexposed area [24]. Moreover, the prevalence of intellectual impairment was higher among the general population 
of Minamata (high-exposure area) than in a low-exposure area. Prenatal or postnatal MeHg exposure is believed to be associated with intellectual impairment [17]. The borderline intellectual functioning of case 2 might be the result of neurodevelopmental disturbance from high prenatal MeHg exposure. The four participants, who were all exposed to high levels of $\mathrm{MeHg}$, had neurologic signs consistent with a diagnosis of Tsubaki's criteria. Moreover, the Japanese Society of Psychiatry and Neurology noted that sensory disturbance of the bilateral distal extremities could be used as the gold standard for diagnosis of Minamata Disease in exposed areas [25]. The four participants, who were all exposed to high levels of $\mathrm{MeHg}$, had sensory disturbances of the bilateral distal extremities.

Accordingly, they could be diagnosed as having Minamata disease. However, they have not been formally recognised as Minamata disease patients and not properly compensated.

Two-points discrimination at the lower lip was impaired in cases 2,3 , and 4 but normal in case 1 . Although sensory disturbance caused by $\mathrm{MeHg}$ poisoning is considered to have been induced from damage to granule cells in the cerebral cortex (somatosensory area) [26], some individuals who have $\mathrm{MeHg}$ poisoning have a normal result in twopoints discrimination testing [27].

Case 1 had perioral sensory disturbance at age 30, which later disappeared, and emerged again at the age of 48. Although she had sensory disturbances on the left side of her body at age 30 , the sensory disturbances were on the right side of her body at age 40 and disappeared at age 48 . Such variation in neurologic signs is characteristic of Minamata disease $[27,28]$ and is probably caused by damage to the cerebral cortex from $\mathrm{MeHg}$ exposure.

Case 4 had no sensory disturbance of the bilateral distal extremities until age 50. Animal studies resulted in multiple cases of delayed $\mathrm{MeHg}$ neurotoxicity $[29,30]$, and there are reports of delayed MeHg-induced neurotoxicity in humans $[31,32]$. The sensory disturbance in case 4 was probably caused by delayed neurotoxicity from $\mathrm{MeHg}$ exposure.

Some individuals exposed to high levels of prenatal and postnatal $\mathrm{MeHg}$ do not develop serious symptoms [33]. Although the four participants had high prenatal and postnatal exposures to $\mathrm{MeHg}$, they did not develop symptoms resembling cerebral palsy, which are common among patients with congenital Minamata disease. However, the four have had subjective symptoms such as poor concentration and poor memory which are thought to be neuropsychological dysfunction, as well as MeHg poisoning in childhood, and neurologic signs such as sensory disturbances of the bilateral distal extremities in adulthood. The reason of lack of symptoms resembling cerebral palsy is unclear. There are several limitations in the present study. First, we included only four participants and we do not have information of exposed residents who did not participate. Thus, there is a possibility of selection bias. Moreover, participants and their data were not collected systematically as a research project, but were documented as they sought clinical care and treatment. Third, it is not clear if the measured Hg level in any subject was actually the peak exposure. Consequently, a single hair $\mathrm{Hg}$ value may not reflect the actual exposure.

\section{Conclusions}

We described the subjective symptoms in childhood and neurologic signs inadulthood of four individuals who were exposed to prenatal and postnatal MeHg. Although they were exposed to high concentrations of $\mathrm{MeHg}$, they did not develop severe symptoms resembling cerebral palsy. However, since childhood they have had subjective symptoms such as poor concentration and poor memory which are thought to be neuropsychological dysfunction, as well as $\mathrm{MeHg}$ poisoning in childhood. At present, nearly 50 years after prenatal and postnatal $\mathrm{MeHg}$ exposure, they had neurologic signs such as sensory disturbances of the bilateral distal extremities and blurred vision.

\section{Acknowledgments}

The authors are grateful to the participants for taking part in this study, and truly grateful to Professor Gray J. Myers from the University of Rochester Rochester,New York for his advice.

\section{References}

1. Harada M (1995) Minamata disease: methylmercury poisoning in Japan caused by environmental pollution. Critical Reviews in Toxicology 25: 1-24.

2. Tsubaki T (1979) Clinical epidemiology about Niigata Minamata Disease In: Arima S (ed) Minamata Disease, Researches during 20 Years and the Problems at Present, Seirinsha, Tokyo, Japan.

3. Ministry of Health and Welfare (1967) Research on diagnosis of the mercury poisoning. In: Special Research Report on Organic Mercury poisoning in Niigata, Ministry of Health and Welfare, Tokyo, Japan.

4. Tsubaki T (1968) Organic mercurial poisoning along the Agano River. Internal Medicine 21: 871-875.

5. Tsubaki T (1968) Methylmercury poisoning along the Agano River, researches by Niigata University. Clinical Neurology 8: 511-520.

6. Tsubaki T (1972) The follow up of Niigata Minamata Disease. Science 42 526-531.

7. Myers G, Davidson P, Weiss B (2004) Methyl mercury exposure and poisoning at Niigata, Japan. Seychelles Medical and Dental Journal 7: 138-148.

8. Maruyama K, Yorifuji T, Tsuda T, Sekikawa T, Nakadaira H, et al. (2012) Methy mercury exposure at Niigata, Japan: results of neurological examinations of 103 adults. Journal of Biomedicine \& Biotechnology 2012: 1.

9. Niigata Prefecture Department of Welfare and Public Health, "Outline of Niigata Minamata Disease," Niigata Prefecture, Japan, March 2002 (Japanese)

10. Saito H (2009) Niigata Minamata Disease; Methylmercury Poisoning in Niigata Japan, Niigata Nippo Jigyosha, Niigata, Japan.

11. Ministry of Health and Welfare (1967) Epidemiological research on the mercury poisoning, in Special Research Report on Organic Mercury Poisoning in Niigata, Ministry of Health and Welfare, Tokyo, Japan 1-58

12. World Health Organization (1976) Environmental Health Criteria 1: Mercury, World Health Organization, Geneva, Switzerland.

13. World Health Organization (1990) Environmental Health Criteria: 101. Methy Mercury, World Health Organization, Geneva, Switzerland.

14. Tsubaki T, Irukayama K (1977) Minamata disease. Amsterdam, Oxford, Elsevier Science Publishers, New York, USA

15. Yorifuji T, Tsuda T, Inoue S, Soshi Takao S, Harada M, et al. (2013) Critical Appraisal of the 1977 Diagnostic Criteria for Minamata Disease. Archives of Environmental and Occupational Health 68: 22-29.

16. Harada M (1978) Congenital Minamata disease: intrauterine methylmercury poisoning,Teratology 18: $285-288$

17. Yorifuji T, Tsuda T,Inoue S, Soshi Takao S, Harada M (2011) Long-term exposure to methylmercury and psychiatric symptoms in residents of Minamata, Japan. Environment International 37: 907-913.

18. Ministry of Health and Welfare (2004) Mercurial analysis manual. Ministry of Health and Welfare, Tokyo, Japan.

19. Ekino S, Ninomiya T, Imamura K, Susa M (2007) Methylmercury causes Diffuse Damage to the Somatosensory Cortex: How to Diagnose Minamata Disease. Psychiatria et Neurologia Japonica 109: 420-437.

20. Hosokawa H, Noda K, Misumi H, Kakita T, Kojima T (1979) A survey of the strange disease in Minamata: In Minamata Disease, Rresearches during 20 Years and the Problems at Present, Tokyo, Japan.

21. Kitamura S, Kakita T, Ogi J, Kojima T (1960) Results of epidemiologica investigations of Minamata disease. Journal of Kumamoto Medical society 43. 
Citation: Maruyama K, Saito H, Hagino N (2015) Prenatal and Postnatal Methylmercury Exposure in Niigata, Japan: Four Cases Descriptive Study. J Clin Case Rep 5: 520. doi:10.4172/2165-7920.1000520

22. Grandjean P, Weihe P, White RF, Debes F, Araki S, et al. (1997) Cognitive deficit in 7-year-old children with prenatal exposure to methylmercury". Neurotoxicology and Teratology 19: 417-428.

23. The Ministry of Environment \& Niigata Prefecture (2010) Guidelines for Applications for Grants for Patients of Minamata Disease IV.

24. Harada M, Tajiri M (2009) An epidemiological and clinical study of infantile and congenital Minamata Disease - A consideration of the effects of methylmercury on fetal and infantile development. Shakaikankei Kenkyu 14: 1-66.

25. The Committee on Research Human Right in The Japanese Society of Psychiatry and Neurology (1998) An opinion ona the criteria on acquired Minamata disease. Psychiatria et Neurologia Japonica 100: 765-790.

26. Ekino S, Susa M, Ninomiya T, Imamura K, Kitamura T (2007) Minamata disease revisited: an update on the acute and chronic manifestations of methyl mercur poisoning. Journal of the Neurological Sciences 262: 131-144.

27. http://www.kyouritsu-cl.com/minamatabyou.html\#4. pdf.
28. K. Tsuruta (2000) Studies of Sensory Disturbance Related to Minamata Disease.Minamata-byo Kenkyu II, Ashi-shobou, Fukuoka, Japan.

29. Spyker JM (1975) Assessing the impact of low level chemicals on development: behavioral and latent effects. Federation Proceedings 34: 1835-1844.

30. Rice DC (1996) Evidence for Delayed Neurotoxicity Produced by Methylmercury. Neurotoxicology 17: 583-596.

31. Shirakawa K (1979) Delayed onset of Minamata disease," in Minamata Disease, Rresearches during 20 Years and the Problems at Present, Seirinsha, Tokyo, Japan.

32. Davis LE, Kornfeld M, Mooney HS, Fiedler KJ, Haaland KY, et al. (1994) Methylmercury poisoning: long-term clinical, radiological, toxicological, and pathological studies of an affected family. Annals of Neurology 35: 680- 688.

33. Saito H, Sekikawa T, Taguchi J, Shozawai T, Kinoshita Y, et al. (2004) Prenata and postnatal methyl mercury exposure in Niigata, Japan: adult outcomes. Seychelles Medical and Dental Journal 7: 138-146. 